\title{
Posterior cruciate ligament injuries: what do we really know?
}

\author{
Philipp W. Winkler ${ }^{1,2}$ (D) Jonathan D. Hughes ${ }^{1} \cdot$ James J. Irrgang ${ }^{1,3} \cdot$ Jón Karlsson $^{4} \cdot$ Volker Musahl $^{1}$
}

Received: 3 December 2020 / Accepted: 18 December 2020 / Published online: 23 January 2021

(c) The Author(s) 2021

\section{Abbreviations}

ACL Anterior cruciate ligament

PCL Posterior cruciate ligament

PLC Posterolateral corner corner (PLC) insufficiency in a recently treated patient in the outpatient clinic of the Department of Orthopedic Surgery in Pittsburgh. In an effort to provide the best and most evidence-based scientific knowledge, we felt compelled to

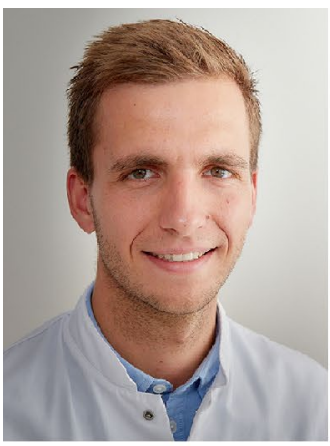

Philipp W. Winkler

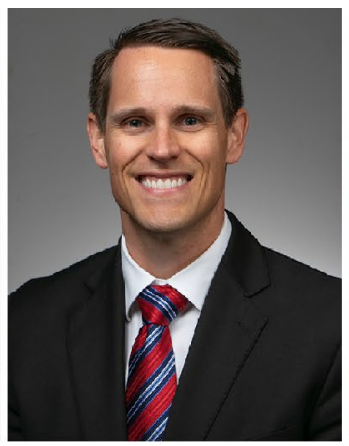

Jonathan D. Hughes

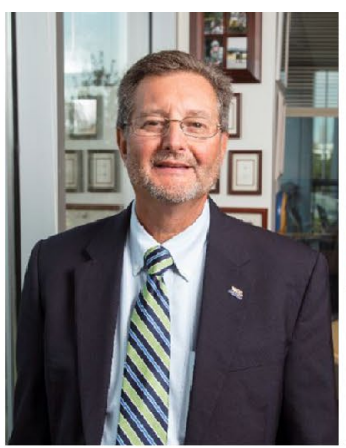

James J. Irrgang

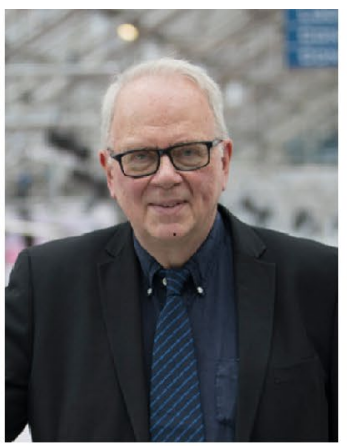

Jon Karlsson

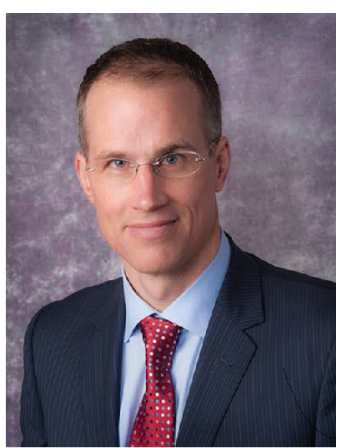

Volker Musahl
Severe anterior knee pain, an increasing feeling of instability, and a striking hyperextension-varus thrust [16] (i.e., triple varus) clearly demonstrated the devastating effects of recurrent posterior cruciate ligament (PCL) and posterolateral

The editorial was written at the Department of Orthopaedic Surgery, University of Pittsburgh, Pittsburgh, PA, USA.

Volker Musahl

musahlv@upmc.edu

1 Department of Orthopaedic Surgery, UPMC Freddie Fu Sports Medicine Center, University of Pittsburgh, 3200 S. Water St, Pittsburgh, PA 15203, USA

2 Department for Orthopaedic Sports Medicine, Klinikum Rechts der Isar, Technical University of Munich, Ismaninger Str. 22, 81675 Munich, Germany

3 Department of Physical Therapy, University of Pittsburgh School of Health and Rehabilitation Sciences, Suite 210, 100 Technology Drive, Pittsburgh, PA 15219, USA

4 Department for Orthopaedics, Sahlgrenska University Hospital, Institute of Clinical Sciences, Sahlgrenska Academy, Gothenburg University, Gothenburg, Sweden review the literature and present the current standard of care for isolated, combined, and recurrent PCL injuries [21, 22]. The comprehensive literature review has opened our eyes. What do we actually know about PCL graft failures and recurrent instability? Was the cause of surgical PCL graft failure in the presented patient an inappropriate graft choice, non-anatomic tunnel placement, underlying bony deformities, wrong timing, non-compliance of the patient, bad luck, or even the decision for operative treatment?

Let's go back to the basics. The central pivot of the human knee joint is represented by the cruciate ligaments, providing not only translational but also rotatory knee stability [8]. While research on the anterior cruciate ligament (ACL) is constantly increasing over the past 40 years, research until the early 1990s hardly focused on the ACL's big brotherthe PCL-which is thicker, stronger, and represents the primary restraint against posterior tibial translation $[1,11,12]$. Most probably, we can learn something from the intensive research and the already established knowledge about the ACL to translate this into the management of PCL injuries. 
What has Freddie Fu taught us about the ACL? "Respect nature". Consequently, years of hard work and intensive research have enhanced our knowledge. Isometric ACL reconstruction has been replaced by anatomic ACL reconstruction, and more recently, individualized anatomic ACL reconstruction combines all our knowledge of functional anatomy, grafts and individual bony morphology to good clinical outcomes [9, 15]. "Respect the past and embrace the future". How can we use this advice and translate it to the management of PCL injuries is an important question?

While the concept of anatomic double-bundle ACL reconstruction has not been proven to be superior to individualized anatomic single-bundle ACL reconstruction [10], this may be different for PCL reconstruction. There is biomechanical evidence that has demonstrated favorable results in restoring native knee kinematics and laxity for doublebundle vs. single-bundle PCL reconstruction [6]. Doublebundle PCL reconstruction requires thorough anatomical knowledge for accurate tunnel placement, and although biomechanical evidence exists, we are still waiting for clinical proof that double-bundle PCL reconstruction is superior to single-bundle PCL reconstruction [13, 23]. Accordingly, the concept of graft configuration (single bundle vs. double bundle) may be of secondary importance, while the graft choice (autograft vs. allograft) may be of primary importance. At least in ACL reconstruction, it can be observed that autografts and especially quadriceps tendon autografts are becoming increasingly popular due to low surgical graft failure rates [5, 19].

When we respect the nature, it is also crucial to take a close look at the individual bony morphology. Biomechanical evidence supports that frontal and sagittal lower limb malalignment affect the stress experienced by the PCL and PLC grafts [3]. It has been shown that more than $30 \%$ of PCL reconstruction failures are associated with varus malalignment [17]. Concurrent realignment osteotomies may improve functional outcomes and increase arthroplasty-free survival, by protecting concurrent ligament reconstructions and preventing subsequent meniscal and cartilage injuries [3, $18,20]$. Therefore, we call for the assessment and, if necessary, correction of frontal and sagittal lower limb deformities in the operative management of PCL injuries.

There is one more topic to discuss. Should we even recommend PCL reconstruction or is a non-operative treatment including functional bracing, intensive physical therapy, and neuromuscular retraining sufficient? In patients with symptomatic grade three PCL injuries, YES, we recommend PCL reconstruction. Especially in young and active patients to avoid subsequent meniscal and cartilage injuries and a rapid development of osteoarthritis [2]. The far more controversial question, however, is: what is the ideal timing for PCL reconstruction (early vs. delayed)? While evidence supports early reconstruction in patients with ACL injuries, research continues to find answers to this controversial question in patients with PCL and multiple ligament knee injuries [4, $7,14]$. One such research project is the STaR Trial (Surgical Timing and Rehabilitation of multiple ligament knee injuries). The STaR Trial is a large-scale multicenter randomized controlled trial that aims at assessing the effect of timing of surgery, early vs. delayed, and timing of rehabilitation, again early vs. delayed on clinical outcome and return to military and civilian duty/sport. The STaR Trial is being conducted across 25 centers in North America with the University of Pittsburgh as the principal site [14].

This editorial highlights numerous controversies in the management of PCL injuries and appeals to all basic scientists and clinical researchers to continue their vigorous efforts to find more evidence. Given the low incidence of PCL injuries, large-scale studies with a high level of evidence (i.e., randomized controlled trials) are currently missing/on the way. Large-scale prospective clinical studies are required to shed light on controversial topics. Never forget, "Respect the past and embrace the future". Therefore, we look with great curiosity into the future of PCL research.

Acknowledgements Not applicable.

Author contributions All listed authors have contributed substantially to this work: PWW and JDH performed primary manuscript preparation. VM, JJI and JK assisted with editing and final manuscript preparation. All authors read and approved the final manuscript.

Funding Open Access funding enabled and organized by Projekt DEAL. No funding was received.

\section{Compliance with ethical standards}

Conflict of interest JJI is the Principal Investigator for the STaR Trial for Mulitple Ligament Knee Injuries and funding is received by the University of Pittsburgh from the US Department of Defense (contract No. W81XWH-17-2-0073). VM reports educational grants, consulting fees, and speaking fees from Smith \& Nephew plc, educational grants from Arthrex, is a board member of the International Society of Arthroscopy, Knee Surgery and Orthopaedic Sports Medicine (ISAKOS), and deputy editor-in-chief of Knee Surgery, Sports Traumatology, Arthroscopy (KSSTA). In addition, VM has a patent Quantified injury diagnostics-U.S. Patent No. 9,949,684, Issued on April 24, 2018 issued to University of Pittsburgh.

Ethical approval Not applicable.

Informed consent Not applicable.

Open Access This article is licensed under a Creative Commons Attribution 4.0 International License, which permits use, sharing, adaptation, distribution and reproduction in any medium or format, as long as you give appropriate credit to the original author(s) and the source, provide a link to the Creative Commons licence, and indicate if changes were made. The images or other third party material in this article are included in the article's Creative Commons licence, unless indicated 
otherwise in a credit line to the material. If material is not included in the article's Creative Commons licence and your intended use is not permitted by statutory regulation or exceeds the permitted use, you will need to obtain permission directly from the copyright holder. To view a copy of this licence, visit http://creativecommons.org/licenses/by/4.0/.

\section{References}

1. Amis AA, Gupte CM, Bull AM, Edwards A (2006) Anatomy of the posterior cruciate ligament and the meniscofemoral ligaments. Knee Surg Sports Traumatol Arthrosc 14:257-263

2. Arøen A, Sivertsen EA, Owesen C, Engebretsen L, Granan LP (2013) An isolated rupture of the posterior cruciate ligament results in reduced preoperative knee function in comparison with an anterior cruciate ligament injury. Knee Surg Sports Traumatol Arthrosc 21:1017-1022

3. Bernhardson AS, Aman ZS, DePhillipo NN, Dornan GJ, Storaci HW, Brady AW et al (2019) Tibial slope and its effect on graft force in posterior cruciate ligament reconstructions. Am J Sports Med 47:1168-1174

4. Diermeier T, Rothrauff BB, Engebretsen L, Lynch AD, Ayeni OR, Paterno MV et al (2020) Treatment after anterior cruciate ligament injury: panther symposium ACL treatment consensus group. Knee Surg Sports Traumatol Arthrosc 28:2390-2402

5. Diermeier T, Tisherman R, Hughes J, Tulman M, Baum Coffey E, Fink C et al (2020) Quadriceps tendon anterior cruciate ligament reconstruction. Knee Surg Sports Traumatol Arthrosc 28:2644-2656

6. Harner CD, Janaushek MA, Kanamori A, Yagi M, Vogrin TM, Woo SL (2000) Biomechanical analysis of a double-bundle posterior cruciate ligament reconstruction. Am J Sports Med 28:144-151

7. Herbst E, Hoser C, Gföller P, Hepperger C, Abermann E, Neumayer $\mathrm{K}$ et al (2017) Impact of surgical timing on the outcome of anterior cruciate ligament reconstruction. Knee Surg Sports Traumatol Arthrosc 25:569-577

8. Hirschmann MT, Müller W (2015) Complex function of the knee joint: the current understanding of the knee. Knee Surg Sports Traumatol Arthrosc 23:2780-2788

9. Hofbauer M, Muller B, Murawski CD, van Eck CF, Fu FH (2014) The concept of individualized anatomic anterior cruciate ligament (ACL) reconstruction. Knee Surg Sports Traumatol Arthrosc 22:979-986

10. Hussein M, van Eck CF, Cretnik A, Dinevski D, Fu FH (2012) Individualized anterior cruciate ligament surgery: a prospective study comparing anatomic single- and double-bundle reconstruction. Am J Sports Med 40:1781-1788

11. Kambhampati SBS, Vaishya R (2020) Publication trends of PCL in the last 40 years on PubMed. J Clin Orthop Trauma 11:s354-s361
12. Kambhampati SBS, Vaishya R (2019) Trends in publications on the anterior cruciate ligament over the past 40 years on PubMed. Orthop J Sports Med 7:2325967119856883

13. Li Y, Li J, Wang J, Gao S, Zhang Y (2014) Comparison of singlebundle and double-bundle isolated posterior cruciate ligament reconstruction with allograft: a prospective, randomized study. Arthroscopy 30:695-700

14. Lynch AD, Chmielewski T, Bailey L, Stuart M, Cooper J, Coady C et al (2017) Current concepts and controversies in rehabilitation after surgery for multiple ligament knee injury. Curr Rev Musculoskelet Med 10:328-345

15. Musahl V, Plakseychuk A, VanScyoc A, Sasaki T, Debski RE, McMahon PJ et al (2005) Varying femoral tunnels between the anatomical footprint and isometric positions: effect on kinematics of the anterior cruciate ligament-reconstructed knee. Am J Sports Med 33:712-718

16. Naudie DD, Amendola A, Fowler PJ (2004) Opening wedge high tibial osteotomy for symptomatic hyperextension-varus thrust. Am J Sports Med 32:60-70

17. Noyes FR, Barber-Westin SD (2005) Posterior cruciate ligament revision reconstruction, part 1: causes of surgical failure in 52 consecutive operations. Am J Sports Med 33:646-654

18. Petrigliano FA, Suero EM, Voos JE, Pearle AD, Allen AA (2012) The effect of proximal tibial slope on dynamic stability testing of the posterior cruciate ligament- and posterolateral corner-deficient knee. Am J Sports Med 40:1322-1328

19. Runer A, Csapo R, Hepperger C, Herbort M, Hoser C, Fink C (2020) Anterior cruciate ligament reconstructions with quadriceps tendon autograft result in lower graft rupture rates but similar patient-reported outcomes as compared with hamstring tendon autograft: a comparison of 875 patients. Am J Sports Med 48:2195-2204

20. Sanders TL, Pareek A, Barrett IJ, Kremers HM, Bryan AJ, Stuart $\mathrm{MJ}$ et al (2017) Incidence and long-term follow-up of isolated posterior cruciate ligament tears. Knee Surg Sports Traumatol Arthrosc 25:3017-3023

21. Winkler PW, Zsidai B, Wagala NN, Hughes JD, Horvath A, Senorski EH et al (2020) Evolving evidence in the treatment of primary and recurrent posterior cruciate ligament injuries, part 1: anatomy, biomechanics and diagnostics. Knee Surg Sports Traumatol Arthrosc. https://doi.org/10.1007/s00167-020-06357-y

22. Winkler PW, Zsidai B, Wagala NN, Hughes JD, Horvath A, Senorski EH et al (2020) Evolving evidence in the treatment of primary and recurrent posterior cruciate ligament injuries, part 2: surgical techniques, outcomes and rehabilitation. Knee Surg Sports Traumatol Arthrosc. https://doi.org/10.1007/s00167-020-06337-2

23. Yoon KH, Kim EJ, Kwon YB, Kim SG (2019) Minimum 10-Year results of single- versus double-bundle posterior cruciate ligament reconstruction: clinical, radiologic, and survivorship outcomes. Am J Sports Med 47:822-827

Publisher's Note Springer Nature remains neutral with regard to jurisdictional claims in published maps and institutional affiliations. 